\title{
Short term respiratory health effects of ambient air pollution: results of the APHEA project in Paris
}

W Dab, S Medina P Quénel, Y Le Moullec, A Le Tertre, B Thelot, C Monteil, P Lameloise, P Pirard, I Momas, R Ferry, B Festy

\begin{abstract}
Study objective - To quantify the short term respiratory health effects of ambient air pollution in the Paris area.

Design - Time series analysis of daily pollution levels using Poisson regression.

Setting - Paris, 1987-92.
\end{abstract}

Measurements and main results - Air pollution was monitored by measurement of black smoke (BS) (15 monitoring stations), sulphur dioxide $\left(\mathrm{SO}_{2}\right)$, nitrogen dioxide $\left(\mathrm{NO}_{2}\right)$, particulate matter less than $13 \mu \mathrm{m}$ in diameter $\left(\mathrm{PM}_{13}\right)$, and ozone $\left(\mathrm{O}_{3}\right)$ (4 stations). Daily mortality and general admissions to public hospitals due to respiratory causes were considered. The statistical analysis was based on a time series procedure using linear regression modelling followed by a Poisson regression. Meteorological variables, epidemics of influenza $A$ and $B$, and strikes of medical staff were included in the models. The mean daily concentration of $\mathbf{P M}_{13}$ and daily 1 hour maximum of $\mathrm{SO}_{2}$ significantly affected daily mortality from respiratory causes. An increase in the concentration of $P M_{13}$ of $100 \mu \mathrm{g} / \mathrm{m}^{3}$ above its 5 th centile value increased the risk of respiratory death by $17 \%$. $\mathrm{PM}_{13}$ and $\mathrm{BS}$ were also associated with hospital admissions due to all respiratory diseases $(4 \cdot 1 \%$ increased risk when the BS level exceeded its 5 th centile value by $\left.100 \mu \mathrm{g} / \mathrm{m}^{3}\right)$. SO $\mathrm{SO}_{2}$ levels consistently influenced hospital admissions for all respiratory diseases, chronic obstructive pulmonary disease, and asthma. Asthma was also correlated with $\mathrm{NO}_{2}$ levels.

Conclusions - These results indicate that even though the relative risk is weak in areas with low levels of pollution, ambient air pollution, and especially particulate matter and $\mathrm{SO}_{2}$, nonetheless require attention because of the number of people exposed and the existence of high risk groups.

(f Epidemiol Comm Health 1996;50(Suppl 1):S42-S46)

et de Sûreté Nucléaire

Paris

P Pirard

Faculté des Sciences Pharmaceutiques et Biologiques,

Université Paris V

I Momas

B Festy

Correspondence to: Dr W Dab.
After reviewing the international reports published during the $1980 \mathrm{~s}^{1-3}$ this team recommended that a time series study be conducted, for the following reasons: (i) since the Paris region is not a heavily polluted area, the detection of a health impact using traditional epidemiological study designs could not be expected; (ii) exploring the feasibility of a monitoring system that could function routinely might lead to other public health benefits (ORS had already successfully experimented with such an approach to influenza epidemic surveillance) $;^{45}$ (iii) the required data were available, at acceptable levels of validity and at low cost. This project was implemented under the name ERPURS ("health risk assessment of urban air pollution").

ERPURS was already underway when we were invited to join the APHEA programme in its proposal stage, in 1992. This opportunity allowed us to share design strategies and solutions with other teams working on the same problems, with all the methodological advantages such exchange provides. We report here the results of this APHEA collaboration: an assessment of the impact of ambient air pollution on respiratory mortality and morbidity.

We studied Paris and its inner suburbs, an area of $762 \mathrm{~km}^{2}$, with an average population between 1987 and 1992 of 6140000 (younger than 15 years of age: $17 \cdot 2 \% ; 15-64$ years, $69.7 \%$; older than 64 years, $13 \cdot 1 \%$ ). Various data sources indicate that roughly $30 \%$ of the population smoke tobacco products $(50 \%$, non-smokers; $20 \%$, former smokers).

\section{Methods}

AIR POLLUTION MEASUREMENTS

Air pollution in the Paris region has been monitored since the 1960s. In 1979, AIRPARIF introduced a network of automatic stations. In 1989 (that is, during the APHEA study period), the design of this network was improved, following the recommendations of a group of EEC experts. ${ }^{6}$ There are now three networks for: (i) monitoring background air pollution; (ii) monitoring automobile exhaust, the main source of air pollution in Paris; and (iii) monitoring pollution in areas of high population density. Following the APHEA protocol, we selected only those stations in the background pollution network whose location had remained stable between 1987 and 1992 . 
Fifteen monitoring stations using reflectrometric techniques provided the 24 hour mean concentration of black smoke (BS). Four other stations measured sulphur dioxide $\left(\mathrm{SO}_{2}\right)$ by ultraviolet fluorescence, nitrogen dioxide $\left(\mathrm{NO}_{2}\right)$ by chemiluminescence, suspended particulates with an aerodynamic diameter less than $13 \mu \mathrm{m}\left(\mathrm{PM}_{13}\right)$ by radiometry, and ozone $\left(\mathrm{O}_{3}\right)$, by ultraviolet absorption. These stations are linked to a computer and provide data every 15 minutes. They are calibrated every two weeks.

Data were considered missing for the calculation of the daily mean if data from at least 18 hours in a day were not available. The missing value was then estimated using the average of the stations available for that day if their correlation was above $0 \cdot 7$. If the data for an entire day were missing, the mean concentrations at the other stations were used, weighted by the ratio of the mean value of the missing station over the three month season to the mean value of the other stations for the same period. After this procedure, the percentages of missing values were $0 \%$ for $\mathrm{BS}, 3 \%$ for $0_{3}, 5 \%$ for $\mathrm{SO}_{2}$ and $\mathrm{NO}_{2}$, and $6 \%$ for $\mathrm{PM}_{13}$. The levels of the various pollutants were very similar at all stations. A specific study of BS showed that its temporal patterns were also very similar from station to station. ${ }^{7}$ Aggregation (taking the arithmetic mean) of the data from each station seems to be a reasonable procedure for estimating global exposure to background air pollution in Paris.

\section{OTHER ENVIRONMENTAL FACTORS}

Meteorological variables (mean daily temperature and relative humidity) and epidemics of influenza $\mathbf{A}$ and $\mathbf{B}$ (two epidemics were detected during the 1988-89 and 1989-90 winters $)^{8}$ were considered to be potential confounders and were included in the modelling process.

The Paris climate is temperate and maritime. The mean (SD) daily temperature $\left({ }^{\circ} \mathrm{C}\right)$ is: $5 \cdot 1$ (4) in winter; 11.7 (5) in spring; 19.0 (4) in summer; and 12.3 (5) in autumn. Relative humidity is between 70 and $85 \%$.

\section{HEALTH DATA}

For the ERPURS project, we analysed data on mortality, hospital admissions, paediatric emergency room visits, emergency house calls and work absenteeism. Only the first two of these indices are considered for APHEA.

Mortality data for the period from 1987-90 came from the National Institute for Health and Medical Research (INSERM), which is responsible for the nationwide collection, validation, and coding (according to ICD-9) of causes of death. Only respiratory causes are considered here (ICD-9 codes 460-519).

The Department of Epidemiology of the Assistance Publique-Hôpitaux de Paris provided data on hospital admissions for the period 1 January 1987 to 30 September 1992 . For the purposes of this study, we considered only the 27 public hospitals that admit patients for short term care (all university teaching hospitals, with roughly 800000 emergency and planned admissions each year). At discharge, the attending physician noted the principal diagnosis, coded according to ICD-9. This paper focuses on respiratory disorders (ICD-9 codes 460-519).

\section{STATISTICAL METHODS}

Statistical analysis followed the APHEA protocol and used an autoregressive Poisson model..$^{9}$ The core model was built controlling for long term trends, seasonal, weekly and daily patterns, meteorological factors, influenza epidemics, and holidays. Moreover, we took into account the effects of a strike of medical residents and nurses in public hospitals, because this clearly affected the level of hospital admissions. Only the best fitting transformations and time lags (lag 0,1,2 and cumulative lags over 4 days) are shown.

We give the results of the Poisson regression as the relative risk of a concentration $100 \mu \mathrm{g} /$ $\mathrm{m}^{3}$ greater than: the 24 hour reference value (calculated as the 5th centile of the concentration distribution) for $\mathrm{BS}, \mathrm{PM}_{13}, \mathrm{SO}_{2}$, and $\mathrm{NO}_{2}$; the mean of the 1 hour maxima for $\mathrm{SO}_{2}$, $\mathrm{NO}_{2}$, and $\mathrm{O}_{3}$; and the 8 hour mean reference level of $\mathrm{O}_{3}$. The value of the $\beta$ coefficient, as well as its $\mathrm{SD}$, is also provided.

\section{Results}

LEVELS OF AIR POLLUTANTS IN THE PARIS REGION

Table 1 summarises the pollution data. BS, $\mathrm{PM}_{13}$, and $\mathrm{SO}_{2}$ show a typical seasonal pattern,

Table 1 Summer and winter levels of pollutants $\left(\mu \mathrm{g} / \mathrm{m}^{3}\right)$; Paris 1987-92

\begin{tabular}{|c|c|c|c|}
\hline & Winter & Summer & Total \\
\hline \multicolumn{4}{|l|}{$\mathrm{SO}_{2}-24 \mathrm{~h}:$} \\
\hline $\begin{array}{l}\text { Mean } \\
\text { Median }\end{array}$ & 40.1 & 20.1 & 29.7 \\
\hline $\begin{array}{l}\text { Median } \\
\text { 5th centile }\end{array}$ & 31.3 & 18.3 & 23.0 \\
\hline 5th centile & 8.7 & 6.0 & 7.0 \\
\hline 99th centile & 149.0 & 49.3 & 125.0 \\
\hline \multicolumn{4}{|c|}{$\mathrm{SO}_{2}-$ maxima $1 \mathrm{~h}$ : } \\
\hline Mean & 78.3 & 42.7 & 59.9 \\
\hline Median & 60.7 & 37.0 & 46.7 \\
\hline 5th centile & 17.0 & 13.0 & 14.0 \\
\hline 99th centile & 268.3 & 133.7 & 232.7 \\
\hline \multicolumn{4}{|c|}{ Black smoke-24 h: } \\
\hline Mean & 39.9 & 24.6 & 31.9 \\
\hline Median & 32.3 & 22.3 & 26 \\
\hline 5th centile & 12.6 & 9.8 & 11.0 \\
\hline 99th centile & 137.6 & 67.9 & 123.3 \\
\hline \multicolumn{4}{|l|}{$\mathrm{PM}_{13}-24 \mathrm{~h}:$} \\
\hline Mean & 54.4 & 47.6 & 50.8 \\
\hline Median & 47.5 & 45.7 & 46.5 \\
\hline 5th centile & 25.0 & 15.5 & 19.0 \\
\hline 99th centile & 151.0 & 105.0 & 137.3 \\
\hline \multicolumn{4}{|l|}{$\mathrm{NO}_{2}-24 \mathrm{~h}:$} \\
\hline $\begin{array}{l}\text { Mean } \\
\text { Median }\end{array}$ & 45.6 & 44.4 & 45.0 \\
\hline $\begin{array}{l}\text { Median } \\
\text { 5th centile }\end{array}$ & $\begin{array}{l}43.0 \\
24.3\end{array}$ & $\begin{array}{l}40.7 \\
20.3\end{array}$ & $\begin{array}{l}41.7 \\
22.0\end{array}$ \\
\hline 99th centile & 110.7 & 108.3 & 108.3 \\
\hline \multicolumn{4}{|c|}{$\mathrm{NO}_{2}-$ maxima $1 \mathrm{~h}$ : } \\
\hline Mean & 70.8 & 76.3 & 73.8 \\
\hline Median & 61.7 & 67.3 & 64.3 \\
\hline 5th centile & 40.0 & 35.5 & 37.5 \\
\hline 99th centile & 202.7 & 202.7 & 202.7 \\
\hline \multicolumn{4}{|l|}{$\mathrm{O}_{3}-8 \mathrm{~h}:$} \\
\hline Mean & 11.5 & 42.7 & 27.7 \\
\hline Median & 8.5 & 36.3 & 20.0 \\
\hline 5th centile & 2.3 & 9.7 & 3.0 \\
\hline 99th centile & 51.7 & 121.3 & 110 \\
\hline \multicolumn{4}{|l|}{$\mathrm{O}_{3}-\operatorname{maxima} 1 \mathrm{~h}:$} \\
\hline Mean & 23.2 & 63.1 & 43.9 \\
\hline Median & 20.2 & 57.3 & 36.0 \\
\hline 5th centile & 4.3 & 21.5 & 6.0 \\
\hline 99th centile & 77.7 & 157.7 & 147.0 \\
\hline
\end{tabular}


Table 2 Relation between daily count of deaths from respiratory causes (\%) and air pollutants - Poisson regression. Paris 1987-90

\begin{tabular}{lllllll}
\hline & $\begin{array}{l}\text { Lag } \\
(d)\end{array}$ & $\begin{array}{l}\text { Log transformation } \\
\text { (Y/N) }\end{array}$ & Coefficient $\beta$ & Standard error $\beta$ & $R R$ per $100 \mu g / m^{3}$ & $(95 \%$ CI $)$ \\
\hline Black smoke & 1 & $\mathrm{Y}$ & 0.029552 & 0.020627 & $1 \cdot 071$ & $(0.975,1 \cdot 177)$ \\
$\mathrm{PM}_{13}$ & $0-1$ & $\mathrm{Y}$ & 0.084729 & 0.031912 & 1.168 & $(1 \cdot 041,1 \cdot 310)$ \\
$\mathrm{SO}_{2}-24 \mathrm{~h}$ & 1 & $\mathrm{Y}$ & 0.029229 & 0.016530 & 1.082 & $(0.970,1 \cdot 206)$ \\
$\mathrm{SO}_{2}-1 \mathrm{~h}$ & 1 & $\mathrm{Y}$ & 0.039171 & 0.016355 & 1.085 & $(1.015,1 \cdot 159)$ \\
$\mathrm{NO}_{2}-24 \mathrm{~h}$ & 1 & $\mathrm{~N}$ & 0.000559 & 0.000698 & 1.057 & $(0.922,1 \cdot 213)$ \\
$\mathrm{NO}_{2}-1 \mathrm{~h}$ & 1 & $\mathrm{~N}$ & 0.000226 & 0.000346 & 1.023 & $(0.940,1 \cdot 133)$ \\
$\mathrm{O}_{3}-8 \mathrm{~h}$ & 0 & $\mathrm{~N}$ & 0.000715 & 0.000713 & 1.074 & $(0.934,1 \cdot 235)$ \\
$\mathrm{O}_{3}-1 \mathrm{~h}$ & 0 & $\mathrm{~N}$ & 0.000390 & 0.000545 & 1.040 & $(0.934,1 \cdot 157)$ \\
\hline
\end{tabular}

Core model for mortality from respiratory diseases: $\sin$ and $\cos$ term for 2 years cycle, sin and cos up to 5 th order, year, interaction (years * sin and cos except 3rd order), day of the week, influenza A epidemic (1990, 15 days lag), temperature, humidity (lag 0), interaction (years * temp), 3 days of high mortality in August ' 90.

Table 3 Relation between daily count of hospital admissions for respiratory diseases (\%) and air pollutants - Poisson regression. Paris 1987-92

\begin{tabular}{|c|c|c|c|c|c|c|}
\hline & $\begin{array}{l}\text { Lag } \\
\text { (d) }\end{array}$ & $\begin{array}{l}\text { Log transformation } \\
(Y / N)\end{array}$ & Coefficient $\beta$ & Standard error $\beta$ & $R R$ per $100 \mu \mathrm{g} / \mathrm{m}^{3}$ & $(95 \% C I)$ \\
\hline \multicolumn{7}{|c|}{ Admissions for respiratory causes (ICD-9 460-519): } \\
\hline Black smoke & 0 & $\mathrm{Y}$ & 0.017150 & 0.007129 & 1.041 & $(1 \cdot 007,1 \cdot 075)$ \\
\hline $\mathrm{PM}_{13}$ & 0 & $\mathrm{Y}$ & 0.023881 & 0.011014 & 1.045 & $(1.004,1.087)$ \\
\hline $\mathrm{SO}_{2}-24 \mathrm{~h}$ & $0-2$ & $\mathrm{Y}$ & 0.015180 & 0.006826 & $1 \cdot 042$ & $(1 \cdot 005,1 \cdot 080)$ \\
\hline $\mathrm{SO}_{2}-1 \mathrm{~h}$ & $0-2$ & $\hat{Y}$ & 0.008372 & 0.007129 & 1.018 & $(0 \cdot 988,1 \cdot 048)$ \\
\hline $\mathrm{NO}_{2}-24 \mathrm{~h}$ & 0 & $\mathbf{N}$ & 0.000417 & 0.000227 & $1 \cdot 043$ & $(0.997,1.090)$ \\
\hline $\mathrm{NO}_{2}-1 \mathrm{~h}$ & 0 & $\mathrm{~N}$ & 0.000148 & 0.000109 & $1 \cdot 015$ & $(0.993,1.037)$ \\
\hline $\mathrm{O}_{3}-8 \mathrm{~h}$ & 0 & $\mathrm{Y}$ & 0.006578 & 0.006978 & $1 \cdot 024$ & $(0.975,1.074)$ \\
\hline $\mathrm{O}_{3}-1 \mathrm{~h}$ & 2 & $\mathrm{Y}$ & 0.011838 & 0.006606 & 1.034 & $(0.997,1.073)$ \\
\hline \multicolumn{7}{|c|}{ Admissions for COPD (ICD-9 $490-496$ except 493): } \\
\hline Black smoke & 2 & $\mathrm{Y}$ & -0.019761 & $0 \cdot 015680$ & 0.955 & $(0 \cdot 889,1 \cdot 026)$ \\
\hline $\mathrm{PM}_{13}$ & 2 & $\mathrm{Y}$ & -0.025430 & 0.024698 & 0.954 & $(0.873,1.043)$ \\
\hline $\mathrm{SO}_{2}-24 \mathrm{~h}$ & 0 & $\mathrm{Y}$ & 0.035066 & 0.013552 & 1.099 & $(1 \cdot 023,1 \cdot 180)$ \\
\hline $\mathrm{SO}_{2}-1 \mathrm{~h}$ & 0 & $\mathrm{~N}$ & 0.000494 & 0.000125 & 1.051 & $(1.025,1.077)$ \\
\hline $\mathrm{NO}_{2}-24 \mathrm{~h}$ & 2 & $\mathrm{Y}$ & -0.015157 & 0.024422 & 0.974 & $(0.898,1.058)$ \\
\hline $\mathrm{NO}_{2}-1 \mathrm{~h}$ & 2 & $\mathrm{Y}$ & -0.030848 & 0.022187 & 0.961 & $(0.919,1.014)$ \\
\hline $\mathrm{O}_{3}-8 \mathrm{~h}$ & $0-1$ & $\mathrm{~N}$ & 0.001140 & 0.000625 & $1 \cdot 121$ & $(0.991,1.267)$ \\
\hline $\mathrm{O}_{3}-1 \mathrm{~h}$ & 1 & $\mathbf{N}$ & 0.000414 & 0.000625 & $1 \cdot 042$ & $(0 \cdot 964,1 \cdot 141)$ \\
\hline \multicolumn{7}{|c|}{ Admissions for asthma (ICD-9 493): } \\
\hline Black smoke & 0 & $\mathrm{Y}$ & 0.018114 & 0.014874 & 1.043 & $(0 \cdot 975,1 \cdot 116)$ \\
\hline $\mathrm{PM}_{13}$ & 2 & $\mathrm{~N}$ & -0.000254 & 0.000397 & 0.975 & $(0.902,1.054)$ \\
\hline $\mathrm{SO}_{2}-24 \mathrm{~h}$ & 2 & $\mathrm{Y}$ & 0.025303 & 0.012166 & 1.070 & $(1 \cdot 004,1 \cdot 141)$ \\
\hline $\mathrm{SO}_{2}-1 \mathrm{~h}$ & 2 & $\mathrm{Y}$ & 0.022133 & 0.011716 & $1 \cdot 047$ & $(0.998,1.098)$ \\
\hline $\mathrm{NO}_{2}-24 \mathrm{~h}$ & $0-1$ & $\mathrm{~N}$ & 0.001617 & 0.000530 & $1 \cdot 175$ & $(1 \cdot 059,1 \cdot 304)$ \\
\hline $\mathrm{NO}_{2}-1 \mathrm{~h}$ & $0-1$ & $\mathrm{Y}$ & 0.060407 & 0.023490 & 1.081 & $(1 \cdot 019,1 \cdot 148)$ \\
\hline $\mathrm{O}_{3}-8 \mathrm{~h}$ & 0 & $\mathrm{~N}$ & -0.001297 & 0.000525 & $0 \cdot 878$ & $(0.792,0.974)$ \\
\hline $\mathrm{O}_{3}-1 \mathrm{~h}$ & 1 & $\mathrm{~N}$ & -0.000342 & 0.000368 & 0.965 & $(0 \cdot 898,1 \cdot 038)$ \\
\hline
\end{tabular}

Core model for respiratory diseases: linear and quadratic trend, sin and cos up to 6th order, year, interaction (years $*$ sin and $\cos$ ), days of the week, nurses' strike, holidays, temperature, humidity (lag 0 ), interaction (years * temp).

Core model for COPD: linear trend, sin and cos up to 6th order, year, interaction (years * sin and cos except 5 th order), day of the week, influenza A epidemic (1987, 3 days lag and 1992, 2 days lag), holidays, temperature, humidity (lag 0), interaction (years * temp).

Core model for asthma: linear and quadratic trend, sin and cos up to 6 th order, year, interaction (years * $\sin$ and $\cos$ ), day of the week, influenza B epidemics (1990, 6 days lag and 1991, 8 days lag), holidays, temperature, humidity (lag 0), interaction (years * temp).

but of moderate variability. Acute episodes are observed during the winter. $\mathrm{O}_{3}$ occurs primarily during summer. There is, on the other hand, very little seasonal variation for $\mathrm{NO}_{2}$.

\section{CRUDE DATA FOR RESPIRATORY HEALTH VARIABLES}

Between 1987 and 1990, there were 189169 deaths, that is, a daily average of 37 . The mean number of deaths from respiratory causes was 9 , the median was 8 , and the range was from 1-125.

The mean number of daily hospital admissions for all respiratory causes was 79 (median 77, range 14-175); for asthma, 14 (median 13, range 2-40); and for chronic obstructive pulmonary disease (COPD, ICD-9 codes 490 496, except 493), 12 (median 11, range 0-31).
RELATIONSHIP BETWEEN AIR POLLUTION AND MORTALITY FROM ALL RESPIRATORY CAUSES The daily count of deaths from respiratory causes was significantly associated with the mean daily concentration of $\mathrm{PM}_{13}$ and the daily 1 hour maximum of $\mathrm{SO}_{2}$ (table 2). The greatest relative risk was observed with the $\mathrm{PM}_{13}$ index: an increase of $100 \mu \mathrm{g} / \mathrm{m}^{3}$ above the 5 th centile concentration increased the risk of respiratory mortality by $17 \%$. This association existed with no lag and was strengthened by a log transformation of the particulate concentration series. The relative risk associated with $\mathrm{SO}_{2}$ was less than half that for $\mathrm{PM}_{13}$. The concentration of the preceding day was the best predictor, and the best fit was again obtained by a log transformation of the pollutant series. Although the relative risks were approximately the same for the 24 hour mean concentrations 
of $\mathrm{SO}_{2}$ and $\mathrm{BS}$, they fell short of statistical significance. The photo-oxidant pollutants showed no significant effect on the mortality risk. No relevant interaction between the pollution effects and the season were observed for mortality from respiratory causes.

\section{RELATIONSHIP BETWEEN AIR POLLUTION AND} HOSPITAL ADMISSIONS FOR RESPIRATORY CAUSES We found that 24 hour concentrations of BS, $\mathrm{PM}_{13}$, and $\mathrm{SO}_{2}$ significantly increased the relative risk of hospital admission for respiratory diseases, overall. Again, the strongest association was observed with $\mathrm{PM}_{13}$ : the risk increased $4.5 \%$ when its concentration that same day was $100 \mu \mathrm{g} / \mathrm{m}^{3}$ higher than its reference value. The effects of 24 hour levels of $\mathrm{SO}_{2}$ were constant for the three categories of respiratory disorders. In general, the daily 1 hour peaks yielded lower relative risks; the exception was $\mathrm{O}_{3}$.

The highest relative risk of COPD admissions was obtained with $\mathrm{O}_{3}$ levels, but it did not reach statistical significance. Only $\mathrm{SO}_{2}$ indicators were associated with a significant elevated risk with no lag.

The relationship between the 24 hour level of $\mathrm{NO}_{2}$ and admissions for asthma is the strongest association observed in this study. The relative risk for a concentration $100 \mu \mathrm{g} / \mathrm{m}^{3}$ above the reference value is 1.175 (no lag). The relative risk for the 1 hour $\mathrm{NO}_{2}$ peak is also significant. No relevant interaction between the health effects of the air pollution and the season was detected.

\section{Discussion}

The APHEA project results for the Paris region demonstrate that ambient air pollution has a short term adverse health effect, despite fairly low pollution levels that are below what are usually considered safe concentrations. ${ }^{10}$

Until now, the only epidemiological study of the short term effects of air pollution on the Parisian general population was a descriptive mortality study conducted between 1969 and 1976. ${ }^{11}$ Using a cross correlation time series design that did not take into account the autocorrelation of the data, it reported a significant increase in daily mortality from all causes at concentrations of aerosol acidity greater than $300 \mu \mathrm{g} / \mathrm{m}^{3}$ and of BS greater than $150 \mu \mathrm{g} / \mathrm{m}^{3}$.

An association between respiratory mortality and $\mathrm{SO}_{2}$ has been observed in two other French cities, Lyon and Marseilles. ${ }^{12}$

Our estimation of the risk of respiratory mortality associated with $\mathrm{PM}_{13}$ exposure is close to that estimated by Dockery and Pope ${ }^{13}$ and to the results of Schwartz's meta-analysis. ${ }^{14}$ It should, however, be noted that the Paris network monitors the $\mathrm{PM}_{13}$ and not the $\mathrm{PM}_{10}$ measured in those studies. In addition, during the period of our study, quality assurance programmes for PM measurements were not as advanced as those for BS.

While the association between particulate matter pollution and mortality is consistent with well-documented findings, ${ }^{15-17}$ the re- lationship between air pollution and hospitalisation is not as well established and prompts questions about its external coherence. ${ }^{18}$ Our hospital data concern emergency and planned admissions: the day of the week strongly influenced the admission count (adjusted $\mathrm{R}^{2}=0.84$ in the core model for all respiratory admissions). $\mathrm{SO}_{2}$ did, however, affect hospital admissions for all respiratory disorders, and the relative risks were even higher for patients with such chronic diseases as COPD and asthma. We too have observed the previously reported impact of low levels of air pollution on asthma hospitalisations. ${ }^{19-22}$ The Seattle report is particularly interesting because its statistical procedures allow it to control for autocorrelation and seasonality. It found $\mathrm{PM}_{10}$ to be associated with hospital emergency room visits for asthma. No relationship was observed with $\mathrm{SO}_{2}$. $\mathrm{NO}_{2}$, however, was not measured. ${ }^{23}$

Its ecological design and lack of precise exposure estimates necessitate prudence in drawing any conclusions of causality from our study. The various pollution indicators yielded similar estimates of relative risk. The degree of toxicity of the gases and particulates that we routinely monitor must also be assessed cautiously. The assortment of pollutants measured and of indicators calculated ( 1 hour maxima and 24 hour means) must be considered as proxy indices for the complex phenomenon of air pollution: they do not point specifically and solely to these pollutants.

The size of the population and the use of the influenza monitoring system that permits epidemics to be controlled for are the two greatest strengths of our study. Its primary limitations are the inability to distinguish emergency from planned hospital admissions and the quality of the $\mathrm{PM}_{13}$ measurements.

The absence of relevant interaction between pollutants and season may mean that the effect of the seasons was already taken into account during the modelling process or that the effects of air pollution in Paris are stable throughout the year. The latter suggestion is consistent with the moderate seasonal variability in the region. In a city like Paris it seems reasonable to believe that the time spent outdoors is fairly constant throughout the year. Because the influence of influenza epidemics was removed from the model after seasonal patterns were controlled for, it is difficult to analyse the specific role influenza A may have on COPD and influenza $\mathrm{B}$, on asthma.

Air pollution in the Paris region does indeed have adverse effects on short term respiratory health, as indicated by the weak but consistent relative risks that are characteristic of low pollution areas. The number of persons exposed and the presence of especially vulnerable groups such as those with asthma point to the need for increased attention to these results. Although the risks observed in the general population are weak, it is reasonable to assume that they are much higher among susceptible groups. Our findings for asthma provide support for this hypothesis. 
Mortality and hospital admissions, it must be stressed, are effects that appear late and are very serious. Two directions of research should now be followed. This study ought to be continued on a permanent basis, and its scope extended. The objective should be a more precise estimation of the risks related to constituents of air pollution, such as particulate matter, for which better measurement techniques are now available. Health effects that may be more sensitive to air pollution levels than mortality and hospitalisation include, for example, emergency house calls. These indices should be measured. Since we did not explore a possible harvesting effect (depletion of the vulnerable population after a long period of high pollution), it might also be interesting to undertake extensive time series studies based on individual exposure estimates.

Finally, the meta-analysis of the data collected in the cities collaborating on the APHEA project should improve the assessment of the health risk for low levels of exposure to air pollution.

This study was supported by the European Economic Communities, the French ministries of Health and Environment, the Regional Council of Île-de-France, ADEME and the Medical Studies Department of Electricité de France and Gaz de France.

1 Momas I, Pirard P, Quénel P et al. Pollution atmosphérique urbaine et mortalité: une synthèse des études épi-
démiologiques publiées entre 1980 et 1991. Rev Epidem et Santé Publique 1993;41:30-43.

2 Quénel P, Medina S, Pirard P et al. Impact de la pollution atmosphérique sur la consommation de soins. Pollution Atmosphérique 1993;1:87-102.

3 Quénel P, Medina S, Pirard P et al. Health service based morbidity indicators as a measure of health effects of air morbidity indicators as a measure of health effects of air pollution. A literature

4 Hannoun C, Dab W, Cohen JM. A new influenza surveillance system in France: The Île-de-France GROG. veillance system in France: The Ile-de-France GROG.
I. Principles and methodology. Eur $\mathcal{f}$ Epidemiol 1989;5:

5 Dab W. Quénel P, Cohen JM, Hannoun C. A new influenza surveillance system in France: the Île-de-France GROG.
II. Validity of indicators (1984-1989). Eur $\mathcal{f}$ Epidemiol 1991;7:579-87.3.

6 Beier R, Eerens H, Meinnes G et al. Study on the redesign of Paris air pollution monitoring network. EEC report. Contract B6611-28-88. Brussels: EC, 1990;81.

7 Pirard P, Quénel P, Lameloise P, Le Moullec Y. Étude de l'utilisation d'une moyenne arithmétique des mesures d'un réseau de surveillance comme indicateur de niveau de pollution atmosphérique en milieu urbain. Pollution de mosphérique 1995;36:59-66.

8 Quénel P, Dab W, Hannoun C, Cohen JM. Sensitivity, specificity and predictive values of health service based indicators for the surveillance of influenza A epidemics. Int $\mathcal{F}$ Epidemol 1994;23:849-55.

9 Katsouyanni K, Zmirou D, Spix C. et al. Short term effects of air pollution on health: a European approach using epidemiological time-series data. The APHEA project: background, objectives, design. Eur Resp $\mathcal{F}$ 1995;8:10301038.

10 WHO. Air quality guidelines for Europe. Copenhagen: WHO Regional Publications. European Series No 23, 1987.

11 Loewenstein JC, Bourdel MC, Bertin M. Influence de la pollution atmosphérique ( $\mathrm{SO}_{2}$, poussières) et des conditions météorologiques sur la mortalité à Paris entre 1969 et 1976. Rev Epidem et Santé Publique 1983;31:163-177.

12 Derrienic F, Richardson S, Mollie A, Lellouch J. Short term effects of sulphur dioxide pollution in two French cities. Int $\mathcal{F}$ Epidemiol 1989;18:186-197.

13 Dockery DW, Pope CA III. Acute respiratory effects of particulate air pollution. Annu Rev Public Health 1994;15: 107-32.

14 Schwartz J. Air pollution and daily mortality; a review and meta analysis. Environ Res 1994;64:36-52.

15 Dockery DW, Schwartz J, Spengler J. Air pollution and daily mortality: associations with particulates and acid daily mortality: associations with partic

16 Dockery DW, Pope CA III, Xu X. An association between air pollution and mortality in six US cities. $N$ Engl $\mathcal{F} \mathrm{Med}$ 993;329:1753-9.

17 Ostro $B$. The association of air pollution and mortality: examining the case for inference. Arch Environ Health 1993;48:336-42.

18 Bates $D$. Health indices of the adverse effects of air pollution: the question of coherence. Environ Res 1992;59:336-49.

19 Bates D, Baker-Anderson M, Sizto R. Asthma attack periodcity: a study of hospital emergency visits in Vancouver. Environ Res 1990;51:51-70.

20 Pönka A. Asthma and low level air pollution in Helsinki. Arch Environ Health 1991;46:262-70.

21 Walters S, Griffiths RK, Ayres JG. Temporal association between hospital admissions for asthma in Birmingham and ambient levels of sulphur dioxide and smoke. Thorax 1994;49:133-140.

22 Cody RP, Weisel CP, Birnbanm G, Lioy PJ. The effect of ozone associated with summertime photochemical smog on the frequency of asthma visits to hospital emergency on the frequency of asthma visits to hospital

23 Schwartz J, Slater D, Larson TV, Pierson WE, Koenig JQ. Particulate air pollution and hospital emergency visits for asthma in Seattle. Am Rev Respir Dis 1993;147:826-831. 